\title{
Intra-Arterial Chemotherapy for Retinoblastoma in Infants $\leq 10$ kg: 74 Treated Eyes with 222 IAC Sessions
}

\author{
(D) A. Sweid, (D)B. Hammoud, (D).H. Weinberg, (D) P. Texakalidis, (D). Xu, (D). Shivashankar, (D) M.P. Baldassari, (D) S. Das, \\ (D) R. Ramesh, (DS. Tjoumakaris, (D) C.L. Shields, DD. Ancona-Lezama, DL.-A.S. Lim, DL.A. Dalvin, and (DP. Jabbour
}

\begin{abstract}
BACKGROUND AND PURPOSE: Intra-arterial chemotherapy for retinoblastoma has dramatically altered the natural history of the disease. The remarkable outcomes associated with a high safety profile have pushed the envelope to offer treatment for patients weighing $\leq 10 \mathrm{~kg}$. The purpose was to determine the efficacy and safety of IAC infusions performed in infants weighing $\leq 10 \mathrm{~kg}$ with intraocular retinoblastoma.
\end{abstract}

MATERIALS AND METHODS: A retrospective chart review was performed for patients diagnosed with retinoblastoma and managed with intra-arterial chemotherapy.

RESULTS: The total study cohort included 207 retinoblastoma tumors of 207 eyes in 196 consecutive patients who underwent 658 intra-arterial chemotherapy infusions overall. Of these, patient weights were $\leq 10 \mathrm{~kg}$ in 69 (35.2\%) and $>10 \mathrm{~kg}$ in 127 (64.8\%) patients. Comparison ( $\leq 10 \mathrm{~kg}$ versus $>10 \mathrm{~kg}$ ) revealed that the total number of intra-arterial chemotherapy infusions was 222 versus 436. Periprocedural complications were not significantly different $(2[0.9 \%]$ versus $2[0.5 \%] ; P=.49)$. Cumulative radiation exposure per eye was significantly lower in infants weighing $\leq 10 \mathrm{~kg}\left(5.0 \mathrm{Gym}^{2}\right.$ versus $\left.7.7 \mathrm{Gym}^{2} ; P=.01\right)$. Patients weighing $\leq 10 \mathrm{~kg}$ had a greater frequency of complete tumor regression ( $82.6 \%$ versus $60.9 \% ; P=.02)$. Mean fluoroscopy time was not significantly different $(7.5$ versus $7.2 ; P=.71$ ). There was a significant difference in the frequency of enucleation (16 [21.6\%] versus 52 [39.1\%]; $P=.01)$. Patients weighing $\leq 10 \mathrm{~kg}$ had greater number of aborted procedures (12 [5.4\%] versus 7 [1.6\%]; $P=.01)$. On multivariate analysis, weight $\leq 10$ $\mathrm{kg}$ was not an independent predictor of complications or procedure failure.

CONCLUSIONS: Intra-arterial chemotherapy in patients weighing $\leq 10 \mathrm{~kg}$ is a safe and effective treatment.

ABBREVIATIONS: IAC = intra-arterial chemotherapy; ICRB = International Classification of Retinoblastoma; OA = ophthalmic artery; Rb = retinoblastoma

ntra-arterial chemotherapy (IAC) for retinoblastoma $(\mathrm{Rb})$ has dramatically altered the natural history of the disease. Cure rates, globe salvage, and vision preservation have dramatically increa-

Received November 30, 2019; accepted after revision April 14, 2020

From the Department of Neurosurgery (A.S., J.H.W., V.X., K.S., M.P.B., S.D., S.R., S.T., P.J.) Thomas Jefferson University and Jefferson Hospital for Neuroscience, Philadelphia, Pennsylvania; Department of Pediatric Endocrinology (B.H.), Children Hospital of Philadelphia, Philadelphia, Pennsylvania; Department of Neurosurgery (P.T.), Emory University School of Medicine, Atlanta, Georgia; Ocular Oncology Service (C.L.S., D.A.-L., L.-A.S.L., L.A.D.), Wills Eye Hospital, Thomas Jefferson University, Philadelphia, Pennsylvania; Ocular Oncology Service (D.A.-L.), Instituto de Oftalmologia y Ciencias Visuales, Tecnologico de Monterrey, Monterrey, Mexico; and Department of Ophthalmology (L.A.D.), Mayo Clinic, Rochester, Minnesota.

Data sharing statement: The relevant anonymized patient-level data are available on reasonable request from the authors.

Please address correspondence to Pascal Jabbour, MD, Professor of Neurological Surgery, Chief Division of Neurovascular Surgery and Endovascular Neurosurgery, Thomas Jefferson University Hospital, 901 Walnut St, 3rd Floor, Philadelphia, PA

19107; e-mail: pascal.jabbour@jefferson.edu; @PascaljabbourMD

Indicates article with supplemental on-line table.

http://dx.doi.org/10.3174/ajnr.A6590 sed. ${ }^{1-10}$ Yamane et $\mathrm{al}^{11}$ in 1989 described an IAC delivery technique termed selective ophthalmic artery infusion using a catheter-based approach with an inflated balloon that occludes the supraclinoid internal carotid artery segment distal to the ostium of the ophthalmic artery (OA). Then Abramson et $\mathrm{al}^{12}$ in 2008 refined the Japanese technique in which the ophthalmic artery was superselectively catheterized. Since then several specialized centers have incorporated ophthalmic artery catheterization into the treatment paradigm with the advantage of delivering a high drug concentration to tumoral tissue while maintaining low systemic concentration, thereby avoiding systemic complications. ${ }^{12}$ Moreover, treatment can be delivered in 1 day, and 2-3 sessions can be sufficient for tumor control. ${ }^{4,13,14}$ We have previously reported our 5-year experience with IAC. ${ }^{7,15,16}$ The remarkable outcomes associated with an acceptable safety profile-despite the risks (retinal toxicity)—and advancement in catheter techniques have pushed the envelope to offer treatment for patients weighing $\leq 10 \mathrm{~kg}$. Weight $<10 \mathrm{~kg}$ or age younger than 3 months have previously been exclusion criteria because of the perceived risk of femoral artery access 
complications. ${ }^{8,12}$ However, a case report and a small series have reported successful IAC delivery for infants weighing $\leq 10 \mathrm{~kg} \cdot{ }^{17,18}$ We herein describe our efficacy and safety outcomes in a large series of IAC infusions performed in infants weighing $\leq 10 \mathrm{~kg}$.

\section{MATERIALS AND METHODS}

\section{Cohort Creation}

The study subjects included patients with unilateral or bilateral intraocular $\mathrm{Rb}$ undergoing IAC from February 2008 to June 2016. The population was dichotomized according to weight, $\leq 10 \mathrm{~kg}$ or $>10 \mathrm{~kg}$. The study protocol was reviewed and approved by the institutional review board. Informed consent was waived because of the retrospective design of this study. Ocular exclusion criteria were vitreous hemorrhage, secondary glaucoma, and extension of tumor into the optic nerve, uvea, anterior segment, or extrascleral compartments. Systemic exclusion criteria were history of blood dyscrasia or thrombotic events.

The patient data were retrospectively reviewed for demographic data, including age (months), sex (male, female), race (white, African American, Hispanic, Asian, Arab), hereditary pattern (sporadic, familial), and laterality (unilateral, bilateral). The presenting symptoms and prior treatment details were recorded. Tumor features included the largest basal diameter, thickness, and location and the presence of subretinal seeds and vitreous seeds. The IAC was delivered either as primary therapy in patients who had no previous treatment or as secondary therapy after failure of previous other types of treatment. Treatment-naïve eyes were classified according to the International Classification of Retinoblastoma (ICRB) (Philadelphia) as group A, B, C, D, or E.

\section{Treatment Protocol}

Parents and patients were informed of the risks of ophthalmic artery cannulation, and procedure consents were obtained.

Each patient was examined initially in the office and then under anesthesia with large fundus drawings, photographic documentation, and fluorescein angiographic analysis of all tumors and features in each eye. The decision for IAC was made in consultation with members of the Ocular Oncology Service, the Department of Neurosurgery, and the Department of Pediatric Oncology. Family history and medical history, particularly for thrombotic events, were obtained. This information was used to assess the need for screening tests looking for an increased risk of thrombosis, including factor $\mathrm{V}$ Leiden mutation, methylenetetrahydrofolate reductase mutation, and prothrombin 20-21-0 mutation.

At each 4-week follow-up, a detailed ophthalmic examination was performed by the treating ocular oncologist with photographic, fluorescein angiographic, and ultrasonographic documentation. The planned protocol was to deliver 3 sessions of IAC and after that judge whether further sessions would be necessary. Per protocol, adjunctive therapy, including laser photocoagulation, cryotherapy, plaque radiation therapy, or external-beam radiation therapy, was not delivered. If there was documented tumor recurrence or resistance, then these methods were potentially used.

During follow-up, each eye was assessed for regression of the solid tumor, subretinal seeds, vitreous seeds, and subretinal fluid. Tumor recurrence was documented. Other subsequent ocular treatment modalities were recorded.

\section{Technical Procedure}

After a parent or legal guardian consent, the IAC catheterization procedure was performed in the interventional neuroradiology suite under general anesthesia and continuous electro-physiological monitoring as an outpatient procedure. Anticoagulation with intravenous heparin $(75 \mathrm{IU} / \mathrm{kg}$ ) was delivered. All surfaces in the interventional neuroradiology suite in contact with the patient and all catheters were covered with plastic wrap, avoiding the use of cotton fiber material, including linen towels and patient draping material. After careful preparation of the puncture site in the groin, a $4 \mathrm{~F}$ micropuncture needle was inserted into the femoral artery, and heparin was administered with a target activated clotting time between 200 and 300 seconds. Under fluoroscopic guidance, a Marathon microcatheter (Medtronic) and a Synchro 10 microwire (Stryker) were navigated all the way up from the groin to the ostium of the OA. The tip of the microcatheter was allowed to hook the ostium of the OA, without the aid of the microwire. A superselective injection was subsequently performed to confirm the position of the microcatheter and ascertain the lack of reflux into the internal carotid artery. If the Marathon catheter did not track, then a Prowler-10 microcatheter (Codman \& Shurtleff) was used. If the latter approach was unsuccessful or if the OA was occluded, catheterization of the OA was alternatively performed through the middle meningeal artery collateral to the OA or by using the balloon-assisted technique. The balloon-assisted technique described by Yamane et $\mathrm{al}^{11}$ was used when there was a stenosis at the ostium and no good middle meningeal collateral.

Chemotherapeutic medications included melphalan and topotecan. The melphalan dose was 3, 5, or $7.5 \mathrm{mg}$, increasing with patient age and tumor size, without dosing higher than dose limit, which is $0.5 \mathrm{mg} / \mathrm{kg}$. The topotecan dose was $1 \mathrm{mg}$. All patients received melphalan, and those with more extensive disease, particularly with vitreous seeding, were given additional topotecan. The microcatheter was subsequently flushed with saline to avoid crystallization of the agent in the OA, and angiograms were obtained to rule out thromboembolic complications. Repeat angiography through the microcatheter was performed immediately after the procedure to ensure the patency of the vessels, and the microcatheter was removed. At the end of the procedure, the heparin was reversed with intravenous protamine, and hemostasis was achieved with manual compression of the femoral artery done only by the senior author. The child was monitored for 6 hours before discharge. Oral aspirin (40 mg) was advised for 2 weeks, and topical ophthalmic application of antibiotic-steroid ointment and cycloplegic eye drops was recommended for 2 weeks. Each session of IAC was planned at a 4 -week interval. A blood hemogram was performed at 2 weeks and 4 weeks after the procedure.

\section{Outcome Variables}

The population was divided into $\leq 10-\mathrm{kg}$ and $>10-\mathrm{kg}$ cohorts. The primary outcomes analyzed were the frequency of periprocedural complications related to the IAC, complete tumor regression, and globe enucleation. Secondary outcomes assessed were the duration of the procedure, fluoroscopy time, mean radiation exposure per eye, cumulative radiation exposure, and procedure termination frequency. Globe preservation was considered as a favorable outcome. 
Table 1: Intra-arterial chemotherapy for retinoblastoma in infants weighing $\leq 10 \mathrm{~kg}$ (74 treated eyes with 222 IAC sessions)-patient demographics

\begin{tabular}{|c|c|c|c|c|}
\hline Variable & $\begin{array}{c}\text { Weight } \leq 10 \mathrm{~kg} \text { ( } n=74 \text { Eyes; } \\
35.7 \% \text { of } 69 \text { Patients) }\end{array}$ & $\begin{array}{c}\text { Weight }>10 \mathrm{~kg}(n=133 \text { Eyes; } \\
64.2 \% \text { of } 127 \text { Patients) }\end{array}$ & $P$ Value & $\begin{array}{l}\text { Total }(n=207) \text { Eyes } \\
(\%) \text { of } 196 \text { Patients }\end{array}$ \\
\hline $\begin{array}{l}\text { Age at presentation (months) } \\
(n=196), \text { mean (median, range) }\end{array}$ & $10(9,1-33)$ & $32(23,4-387)$ & .01 & $24(15,1-387)$ \\
\hline $\begin{array}{l}\text { Age at time of first IAC (months) } \\
(n=196), \text { mean (median, range) }\end{array}$ & $11(10,3-30)$ & $35(25,4-387)$ & .01 & $24(15,1-387)$ \\
\hline $\begin{array}{l}\text { Weight at first IAC }(\mathrm{kg})(n=196) \text {, } \\
\text { mean (median, range) }\end{array}$ & $8.4(8.9,3.1-10.4)$ & $16.4(13.3,10.3-209)$ & .01 & $13.5(11.5,3.1-209)$ \\
\hline \multicolumn{5}{|l|}{$\operatorname{Sex}(n=196)$} \\
\hline Male & $36(52.2)$ & $68(53.5)$ & .85 & $104(53.1)$ \\
\hline Female & $33(47.8)$ & $59(46.5)$ & & $92(47.8)$ \\
\hline \multicolumn{5}{|l|}{ Race $(n=196)$} \\
\hline White & $37(53.6)$ & $59(46.5)$ & .31 & $96(49.0)$ \\
\hline Asian & $12(17.4)$ & $26(20.5)$ & & $38(19.4)$ \\
\hline African American & $11(16.0)$ & $21(16.5)$ & & $32(16.3)$ \\
\hline Hispanic & 9 (13.0) & $12(9.4)$ & & $21(10.7)$ \\
\hline Other & 0 & 9 (7.1) & & $9(4.6)$ \\
\hline Family history $(n=196)$ & $4(5.8)$ & $8(6.2)$ & .88 & $12(6.1)$ \\
\hline \multicolumn{5}{|l|}{ Genetics $(n=196)$} \\
\hline Somatic & $31(44.9)$ & $51(40.2)$ & .29 & $82(41.8)$ \\
\hline Germline & $20(28.9)$ & $38(29.9)$ & & $58(29.6)$ \\
\hline 13q deletion syndrome & $2(2.9)$ & $0(0.0)$ & & $2(1.0)$ \\
\hline Unavailable & $16(23.2)$ & $38(29.9)$ & & $54(27.6)$ \\
\hline \multicolumn{5}{|l|}{ Laterality of disease $(n=196)$} \\
\hline Unilateral & 55 (79.7) & $91(71.7)$ & .21 & $146(74.5)$ \\
\hline Bilateral & $14(20.3)$ & $36(28.3)$ & & $50(25.5)$ \\
\hline \multicolumn{5}{|l|}{ Involved eye $(n=196)$} \\
\hline Right eye & $31(41.9)$ & $66(49.6)$ & .19 & $97(49.5)$ \\
\hline Left eye & $43(58.1)$ & $67(50.4)$ & & $110(56.1)$ \\
\hline
\end{tabular}

\section{Statistical Analysis}

Categoric variables were summarized as absolute and relative frequencies and compared with the $\chi$-square test, and continuous variables were presented as means and standard deviations and compared with the $t$ test. A multivariate logistic regression model was developed to assess whether the weight of $\leq 10 \mathrm{~kg}$ was a potential predictor of periprocedural complications and procedure failures. For all tests, a $P$ value $<.05$ was considered statistically significant. All analyses were performed with STATA software (version 14.1; StataCorp).

\section{RESULTS}

The total study cohort included $207 \mathrm{Rb}$ tumors of 207 eyes in 196 consecutive patients who underwent 658 intra-arterial chemotherapy infusions overall. Of these, patient weights were $\leq 10 \mathrm{~kg}$ in $69(35.2 \%)$ and $>10 \mathrm{~kg}$ in $127(64.8 \%)$ patients. Of the 69 patients weighing $\leq 10 \mathrm{~kg}$, 5 patients received IAC treatment for bilateral $\mathrm{Rb}$, and of the 127 patients weighing $>10 \mathrm{~kg}, 6$ patients received IAC treatment for bilateral $\mathrm{Rb}$. Thus, a total of 74 eyes of 69 patients weighing $\leq 10 \mathrm{~kg}$ were compared with 133 eyes of 127 patients weighing $>10 \mathrm{~kg}$.

\section{Patient Demographics}

Comparison ( $\leq 10 \mathrm{~kg}$ versus $>10 \mathrm{~kg}$ ) revealed a significant difference of age at presentation of 10 months (median 9, range 1-33) versus 32 months (median 23, range 4-387) $(P=.01)$, age at first IAC treatment of 11 months (median 10, range 3-30) versus 35 months (median 25, range 4-387) $(P=.01)$, and weight at first
IAC treatment of $8.4 \mathrm{~kg}$ (median 8.9, range 3.1-10.4) versus 16.4 (median 13.3, range 10.3-209) $(P=.01)$. There was no difference in the distribution of sex proportions between groups: 36 male patients (52.2\%) and 33 female patients (47.8\%) versus 68 male patients $(53.5 \%)$ and 59 female patients $(46.5 \%)(P=.85)$. Also, no significant difference in race distribution was observed: 37 (53.6\%) versus 59 (46.5\%) whites; $12(17.4 \%)$ versus 26 (20.5\%) Asians; 11 (16.0\%) versus 21 (16.5\%) African Americans; 9 (13.0\%) versus 12 (9.4\%) Hispanics; and 0 versus 9 (7.1\%) others $(P=.31)$. There was no difference in family history of Rb among both groups: 4 (5.8\%) versus $8(6.2 \%)(P=.88)$.

Comparison ( $\leq 10 \mathrm{~kg}$ versus $>10 \mathrm{~kg}$ ) revealed no significant difference in genetic mutations: 31 patients (44.9\%) versus 51 patients (40.2\%) with somatic mutations; 20 patients (28.9\%) versus 38 patients $(29.9 \%)$ with germline mutations; 2 patients (2.9\%) versus 0 patients with $13 \mathrm{q}$ deletion syndrome; and 16 patients (23.2\%) versus 38 patients (29.9) with unknown status $(P=.29)$. There was no difference in disease laterality: 55 patients (79.7\%) versus 91 patients $(71.7 \%)$ with unilateral involvement; 14 patients $(20.3 \%)$ versus 36 patients $(28.3 \%)$ with bilateral involvement $(P=.21)$ or right and left eye involvement; 31 (41.9\%) versus 66 (49.6\%) right eye involvement; and 43 (58.1\%) versus 67 (50.4\%) left eye involvement $(P=.19)$ (Table 1).

\section{Tumor Features}

Comparison of tumor characteristics $(\leq 10 \mathrm{~kg}$ versus $>10 \mathrm{~kg}$ ) revealed no difference in greatest basal diameter: $15.0 \mathrm{~mm}$ (median 16, range 3-24) versus $16.0 \mathrm{~mm}$ (median 16, range 4-24) 
$(P=.25)$. Patients weighing $\leq 10 \mathrm{~kg}$ had lower tumor thickness: $7.2 \mathrm{~mm}$ (median 6.5, range 1-17) versus $8.4 \mathrm{~mm}$ (median 8 , range 1-22) $(P=.04)$ and shorter tumor distance to the foveola $0.7 \mathrm{~mm}$ $(0,0-11)$ versus $2.4 \mathrm{~mm}(0,0-15)(P=.01)$ and optic disc $0.8 \mathrm{~mm}$ $(0,0-8)$ versus $2.0 \mathrm{~mm}(0,0-18)$. There was no significant difference in subretinal seeding: 30 eyes $(40.5 \%)$ versus 51 eyes (38.3) $(P=.75)$. Patients weighing $\leq 10 \mathrm{~kg}$ had a lower frequency of vitreous seeding: 18 eyes $(24.3 \%)$ versus 70 eyes $(52.6 \%)(P=.01)$. There was no significant difference in anterior chamber seeding: 0 $(0.0 \%)$ eyes versus 1 eye $(0.7 \%)(P=.45)$. Patients weighing $\leq 10$ $\mathrm{kg}$ presented with less advanced Rb ICRB stage: 12 (16.9\%) versus 5 (4.2\%) with stage B, 9 (12.7\%) versus 6 (5.0\%) with stage C, 34 $(47.9 \%)$ versus $58(48.3 \%)$ with stage $\mathrm{D}$, and $16(22.5 \%)$ versus 51 (42.5\%) with stage $\mathrm{E}(P=.01)$ (On-line Table).

\section{Treatment Features and Periprocedural Complications}

Comparison of treatment details ( $\leq 10 \mathrm{~kg}$ versus $>10 \mathrm{~kg}$ ) revealed that the total number of IAC infusions was 222 versus 436 (Fig $1 A$ ). There was no difference in primary, 38.0 eyes (51.3\%) versus 66.0 eyes (49.6\%), or secondary IAC treatment, 36.0 eyes (48.6\%) versus 67.0 eyes $(50.3 \%)(P=.85)$. There was no significant difference in number of IAC infusions per eye: 3.0 cycles (median 3, range 1-8) versus 3.3 cycles (median 3 , range $1-9)(P=.26)$. There was no significant difference in the technique of IAC delivery by using selective OA catheterization: 206.0 (95.4\%) versus 397.0 (92.9\%) or an alternative approach such as balloon-assisted delivery: 6.0 (2.7\%) versus $13.0(3.0 \%)$ or middle meningeal artery $4.0(1.9 \%)$ versus $17.0(3.9 \%)(P=.65)$. There was a shorter procedure duration in infants weighing $\leq 10 \mathrm{~kg}$ : 47.5 minutes (median 42, range 6-156) versus 51.1 (median 48, range 7-200), but this was not statistically significant $(P=.06)$. Mean radiation exposure per eye and cumulative radiation exposure per eye $\left(\mathrm{Gym}^{2}\right)$ were both significantly lower in infants weighing $\leq 10 \mathrm{~kg}(1.7 \pm 2.6,95 \%$ CI $1.0-2.3$ versus $2.6 \pm 3.1,95 \%$ CI 2.0-3.1; $P=.02)$ and $(5.0 \pm 8.1,95 \%$ CI $3.0-7.0$ versus $7.7 \pm 8.4,95 \%$ CI 6.2-9.2; $P=.01)$, respectively. Mean fluoroscopy time (in minutes) was not significantly different $(7.5 \pm 4.7$, 95\% CI 6.4-8.6 versus 7.2 \pm 7.6 , 95\% CI 5.8-8.5; $P=.71$ ) (Fig $1 B$ ). Patients weighing $\leq 10 \mathrm{~kg}$ had a greater frequency of aborted procedures: $12(5.4 \%)$ versus $7(1.6 \%)(P=.01)$.

Of aborted procedures in infants weighing $\leq 10 \mathrm{~kg}, 50 \%$ were because of inability to secure femoral artery access, but $70 \%$ of aborted cases in patients weighing $>10 \mathrm{~kg}$ were because of a thrombosed OA. Infants weighing $\leq 10 \mathrm{~kg}$ were subgrouped into 3 groups according to weight: group 1, $\leq 4.5 \mathrm{~kg}$; group 2, $4.6-6 \mathrm{~kg}$; and group $3,>6 \mathrm{~kg}$. The incidences of failed femoral access were 0 in the first 2 groups and $2.8 \%$ in the third group $(P=.80)$ (Table 2 and Fig $1 C)$. Of the 6 failed attempts, 5 had previous successful femoral access. The weight, age, and number of successful previous IAC attempts are presented in Table 3.

Periprocedural complications were not significantly different: $2(0.9 \%)$ (vasospasm; 1 OA vasospasm after 5-cc infusion of the chemotherapy and 1 carotid vasospasm after straightening of a 360 carotid loop) versus 2 (0.5\%) (1 incidence of ICA dissection by the microcatheter and 1 anaphylactic shock) $(P=.49)$ (Fig 1D).

\section{Outcomes}

Comparison ( $\leq 10 \mathrm{~kg}$ versus $>10 \mathrm{~kg}$ ) revealed no difference in mean follow-up duration: 31.7 months (median 22.7, range 1.7157.2 ) versus 30.0 (median 23.4, range $0.2-112.4)(P=.73$ ). Patients weighing $\leq 10 \mathrm{~kg}$ had a greater frequency of complete tumor regression: 57 (82.6\%) versus $81(60.9 \%)(P=.02)$. Patients weighing $\leq 10 \mathrm{~kg}$ had lower frequency of enucleation: 16 (21.6\%) versus $52(39.1 \%)(P=.01)$ (Table 4 and Fig $1 E)$.

\section{Multivariate Analysis}

By multivariate logistic analysis, weight $\leq 10 \mathrm{~kg}$ was not an independent predictor of procedural failure (OR: 1.24; 95\% CI: 0.30$5.10, P=.75)$, nor an independent predictor of periprocedural complications (OR: 6.4; 95\% CI: 0.63-65.6, $P=.15$ ).

\section{DISCUSSION}

Endovascular intra-arterial drug delivery is a promising field allowing for selective delivery of a high concentration of a therapeutic drug to selected targets. IAC for Rb stands as an inspiring example of the potential of selective drug delivery. IAC is a notable and established therapeutic option for $\mathrm{Rb}$ that has altered the natural history of the disease. Impressive cure rates have been reported, reaching 97\%, with a dramatic drop in enucleation frequency (Fig 2). ${ }^{2,19-21}$ In a previous report of our 5-year experience with IAC, we found globe salvage rates of $100 \%$ for group B and C eyes, ${ }^{7} 94 \%$ for group D eyes, and $\leq 73 \%$ for group E eyes with a combination of IAC and intravitreal chemotherapy. ${ }^{16}$ Most centers that use IAC for Rb have previously set treatment exclusion criteria for primary IAC of either weight $\leq 10 \mathrm{~kg}$ or age 3 months or younger, mainly because of the perceived risk of femoral artery complications in this group of patients. However, the importance of early treatment stems from data showing that younger and treatment-naïve patients may achieve better oncologic efficacy when they receive a minimal number of IAC cycles. ${ }^{6}$ Gobin et $\mathrm{al}^{22}$ showed that primary treatment with IAC was associated with an event-free survival rate of $81.7 \%$ after 2 years. Such a rate is much higher than $58.4 \%$ for eyes that had received intravenous chemotherapy or external-beam radiation in the pre-IAC era. Few reports exist in the literature on neuroendovascular approaches in infants and in particular on IAC treatment. Herein, we share our experience and report the safety and efficacy of IAC as a primary therapy for Rb in infants weighing $\leq 10 \mathrm{~kg}$.

On review of our data ( $\leq 10 \mathrm{~kg}$ versus $>10 \mathrm{~kg}$ ), procedure duration (47.5 minutes versus 51.1 minutes, $P=.06$ ), fluoroscopy time (7.5 minutes versus 7.2 minutes, $P=.71$ ), cumulative radiation exposure per eye $\left(5.0 \mathrm{Gym}^{2}\right.$ versus $\left.7.7 \mathrm{Gym}^{2} ; P=.01\right)$, percentage of aborted procedures $(5.4 \%$ versus $1.6 \%, P=.01)$, percentage of periprocedural complications $(0.9 \%$ versus $0.5 \%, P=.49)$, percentage of complete tumor regression ( $82.6 \%$ versus $60.9 \%, P=.02$ ), and enucleation frequency $(21.6 \%$ versus $39.1 \%, P=.01)$ speak to the safety and efficacy of IAC for infants $\leq 10 \mathrm{~kg}$ at a high-volume center. Vessel dissection was the only major complication that occurred in 1 patient weighing $>10 \mathrm{~kg}$. Multivariate analysis showed that weight $\leq 10 \mathrm{~kg}$ was not an independent predictor of complications or procedure termination. As expected, the frequency of failed procedures was significantly higher in infants weighing $<10 \mathrm{~kg}$, mainly 


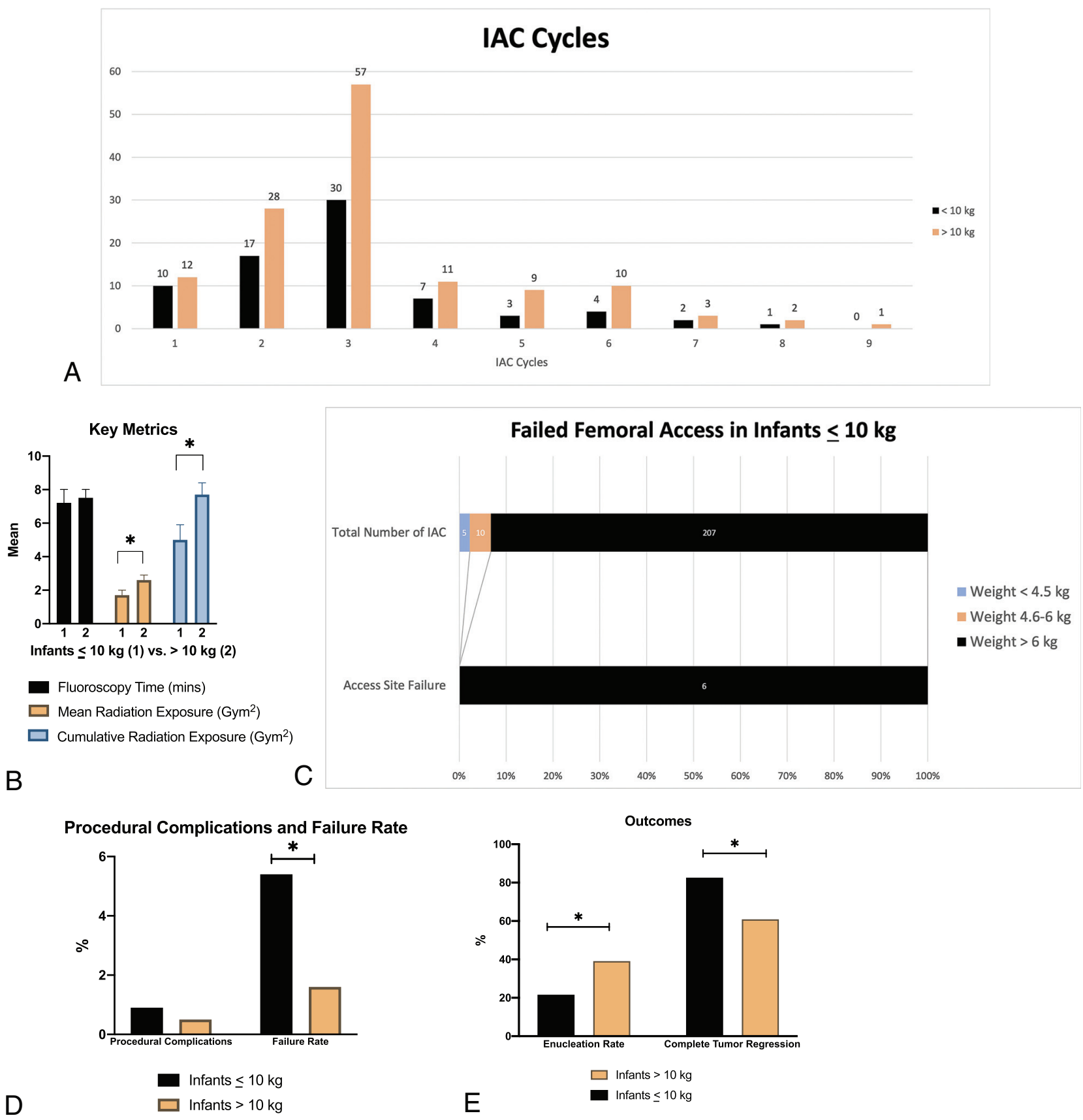

FIG 1. A, Bar graph showing the total number of IAC cycles per eye for infants weighing $\leq 10 \mathrm{~kg}$ and $>10 \mathrm{~kg}$. B, Bar graph showing the mean and standard error of fluoroscopy time (in minutes) and radiation exposure per eye (Gym²) of infants weighing $\leq 10 \mathrm{~kg}$ and $>10 \mathrm{~kg}$. Group 1: infants weighing $\leq 10 \mathrm{~kg}$; group 2: infants weighing $>10 \mathrm{~kg}$. C, Bar graph showing the total number of IAC procedures and absolute value of failed femoral access in infants weighing $\leq 10 \mathrm{~kg}$. Infants weighing $<10 \mathrm{~kg}$ were subgrouped into 3 groups according to weight. D, Bar graph showing the percentage of periprocedural complications and failure rate of infants weighing $\leq 10 \mathrm{~kg}$ and $>10 \mathrm{~kg}$. E, Bar graph showing the enucleation rate and complete tumor regression of infants weighing $\leq 10 \mathrm{~kg}$ and $>10 \mathrm{~kg}$. Asterisks indicates significant difference.

because of inability to secure femoral artery access. Enucleation frequency in patients weighing $<10 \mathrm{~kg}$ was significantly lower compared with those weighing $>10 \mathrm{~kg}$. Such outcomes highlight the fact that earlier treatment is associated with more favorable outcomes because of earlier stage of the cancer.

We previously reported a case of successful treatment of group $\mathrm{D} \mathrm{Rb}$ with IAC in a subject weighing $<6 \mathrm{~kg}$. The subject received 2 cycles of IAC with 5 weeks in between and did well without adverse effects. ${ }^{18}$ Kim et al $^{17}$ retrospectively analyzed outcomes of IAC for $11 \mathrm{Rb}$ eyes in 6 patients whose average weight was $8.9 \mathrm{~kg}$ at the time of the first IAC. They reported excellent overall response to IAC with $100 \%$ globe salvage and minimal access site complications. They encountered 1 hospitalized case of severe neutropenia among 6 patients who developed chemotherapy-induced neutropenia. Chen et $\mathrm{al}^{23}$ retrospectively analyzed 10 patients who started IAC within their first 3 months of life, reporting that 
primary IAC was feasible for the treatment of $\mathrm{Rb}$ in that age group. Most (12/13) eyes were salvaged, and no signs of ischemia were reported. Interestingly, a recent animal model for $\mathrm{Rb}$ reported $100 \%$ success rate in rabbits that weighed $3.0-3.2 \mathrm{~kg}$. ${ }^{24}$

IAC is a challenging procedure that requires an experienced neurointerventionalist competent in the cannulation of very smallcaliber vessels in infants, an experienced anesthesia team, and wellprepared infrastructure. The procedure is not always straightforward because there are several technical, anatomic, and physiologic

Table 2: Intra-arterial chemotherapy for retinoblastoma in infants weighing $\leq 10 \mathrm{~kg}$ (74 treated eyes with 222 IAC sessions)rate of femoral access failure in infants weighing $\leq 10 \mathrm{~kg}$

\begin{tabular}{|c|c|c|c|}
\hline Group $^{a}$ & $\begin{array}{c}\text { Patients } \\
(n)\end{array}$ & $\begin{array}{l}\text { Attempts } \\
(n)\end{array}$ & $\begin{array}{c}\text { Failed Femoral } \\
\text { Access, } \\
n(\%)\end{array}$ \\
\hline 1 & 3 & 5 & $0(0)$ \\
\hline 2 & 4 & 10 & $0(0)$ \\
\hline 3 & 67 & 207 & $6(2.8)$ \\
\hline
\end{tabular}

${ }^{a}$ Infants were subgrouped into 3 groups according to weight: group 1, $\leq 4.5 \mathrm{~kg}$; group 2, 4.6-6 kg; and group 3, > $6 \mathrm{~kg}$.

Table 3: Intra-arterial chemotherapy for retinoblastoma in infants weighing $\leq 10 \mathrm{~kg}$ (74 treated eyes with 222 IAC sessionsweight, age, and number of previous successful attempts for infants of failed femoral access

\begin{tabular}{lccc}
\hline $\begin{array}{c}\text { Patient } \\
\text { No. }\end{array}$ & $\begin{array}{c}\text { Weight } \\
(\mathbf{k g})\end{array}$ & $\begin{array}{c}\text { Age } \\
\text { (months) }\end{array}$ & $\begin{array}{c}\text { Previous Successful } \\
\text { Attempts }(\boldsymbol{n})\end{array}$ \\
\hline 1 & 9.1 & 6.0 & 0 \\
2 & 10.0 & 8.0 & 1 \\
3 & 6.7 & 9.0 & 1 \\
4 & 7.0 & 6.0 & 2 \\
5 & 10.0 & 10.0 & 2 \\
6 & 9.4 & 6.0 & 3 \\
\hline
\end{tabular}

challenges. The minute caliber and fragility of access and target vessels is critical; therefore, sonography-guided femoral access is used for all procedures. In our series, we did not encounter any access site complications in either group. However, the small caliber of the femoral artery led to procedure termination in subjects weighing $\leq 10 \mathrm{~kg}$ at a frequency of $2.7 \%$ because of an inability to secure femoral access. However, it is paramount to know that femoral access is possible even in very young infants of $3 \mathrm{~kg}$ or age of 3 months. A low-profile $4 \mathrm{~F}$ micropuncture kit may be used to gain access and used instead of a $4 \mathrm{~F}$ pediatric sheath. In addition, a microcatheter may be used to complete the procedure without the use of a guide catheter. Sick infants in intensive care units receive a femoral line as a standard practice, and along the same line of thought, young infants eligible for IAC should not be denied the possibility based on weight or age alone. Eighty percent of the aborted IAC procedures due to failed arterial access had at least 1 successful attempt before. There was no incidence of procedure abortion in subjects weighing $>10 \mathrm{~kg}$ because of vascular access. The main reason for procedure termination was OA thrombosis. On multivariate analysis, weight was not an independent predictor of procedure failure.

It is well established from the cardiac literature that larger sheath size relative to the femoral artery diameter is associated with higher rates of femoral artery complications (eg, vasospasm, thrombosis, and arterial disruption). ${ }^{25-27}$ The $4 \mathrm{~F}$ catheter has a diameter of $1.33 \mathrm{~mm}$, which is larger than the size of the femoral artery in subjects weighing $<10 \mathrm{~kg}$. Reports of infants who underwent cardiac catheterization describe $8 \%-14 \%$ femoral artery injury leading to leg length discrepancy, with arterial thrombosis in one-third of cases. ${ }^{28-30}$ Moreover, late arterial complications can occur because of catheter-induced endothelial damage. The senior author performs femoral artery compression at the end of the case for 20 minutes and moniTable 4: Intra-arterial chemotherapy for retinoblastoma in infants weighing $\leq 10 \mathbf{~ k g}$ (74 treated eyes with 222 IAC sessions)-clinical outcomes

\begin{tabular}{|c|c|c|c|c|}
\hline Variable & $\begin{array}{l}\text { Weight } \leq 10 \mathrm{~kg} \\
\text { ( } n=74 \text { Eyes; } \\
35.7 \% \text { of } \\
69 \text { Patients) }\end{array}$ & $\begin{array}{l}\text { Weight }>10 \mathrm{~kg} \\
\text { ( } n=133 \text { Eyes; } \\
64.2 \% \text { of } \\
127 \text { Patients) }\end{array}$ & $\begin{array}{c}P \\
\text { Value }\end{array}$ & $\begin{array}{c}\text { Total }(n=207) \\
\text { Eyes }(\%) \text { of } \\
196 \text { Patients }\end{array}$ \\
\hline $\begin{array}{l}\text { Complete tumor } \\
\text { regression }\end{array}$ & $57(82.6)$ & $81(60.9)$ & .02 & $138(66.6)$ \\
\hline Globe enucleation & $16(21.6)$ & $52(39.1)$ & .01 & $68(32.8)$ \\
\hline $\begin{array}{l}\text { Follow-up duration } \\
\text { (months) ( } n= \\
\text { 196), mean } \\
\text { (median, range) }\end{array}$ & $31.7(22.7,1.7-157.2)$ & $30.0(23.4,0.2-112.4)$ & .73 & $30.6(22.8,0.2-157.2)$ \\
\hline
\end{tabular}
tors the arterial wave by using a pulse oximeter placed on the ipsilateral big toe. The philosophy is that too much compression may result in vessel damage, vasospasm, or limb ischemia, but poor compression may result in retroperitoneal hematoma, which may be disastrous in this age group. Also, the senior author has modified the IAC technique such that he no longer uses a
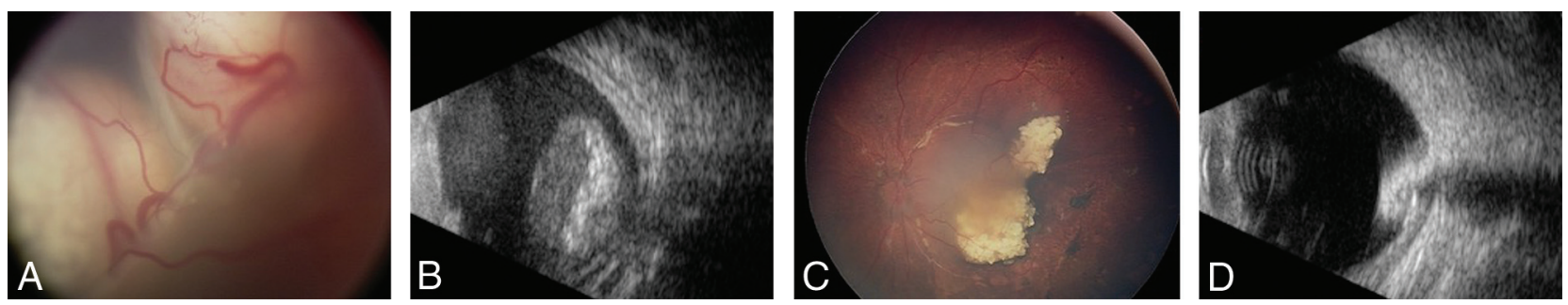

FIG 2. Retinoblastoma $(A$ and $B$ ) before and $(C$ and $D) 9$ months after treatment with intra-arterial chemotherapy (IAC). $A$, An infant presented with left eye leukocoria and unilateral group $E$ retinoblastoma with no view of the optic nerve. $B$, B-scan ultrasonography demonstrated a calcified intraocular mass with overlying retinal detachment and no optic nerve involvement. C, After 4 IAC infusions using melphalan $5 \mathrm{mg}$ and topotecan $1 \mathrm{mg}$, the tumor showed complete response with type III regression to a partially calcified mass in the macular region (D) confirmed by B-scan ultrasonography. 
guide catheter to avoid vessel dissection and to be able to downsize the groin sheath. Rather, catheterization is performed using a Marathon and a Synchro10 wire all the way from the femoral artery to the OA.

\section{Limitations}

Our study has the natural limitations of selection bias in a nonrandomized single-center study. Results have to be interpreted with caution, and conclusions should be validated in a larger population over a longer follow-up period. The strength of our study is a large number of procedures performed by the same group of neurointerventionalists in a single center.

\section{CONCLUSIONS}

$\mathrm{IAC}$ for $\mathrm{Rb}$ is a therapeutic approach that led to dramatic changes in the natural history of the disease. Cure rates, globe salvage, and vision preservation have significantly improved. The long, encouraging experience along with a high safety profile of IAC pushed the envelope to provide this patient population with such an alternative. Our results speak of the safety and efficacy of IAC in patients weighing $\leq 10 \mathrm{~kg}$. Management should be tailored per patient, and variables such as age and weight should not be exclusion criteria to offer IAC.

Disclosures: Stavropoula Tjoumakaris—UNRELATED: Consultancy: Medtronic. Pascal Jabbour-UNRELATED: Consultancy: Microvention*; Grants/grants pending: Medtronic.* *Money paid to institution.

\section{REFERENCES}

1. Schefler AC, Kim RS. Recent advancements in the management of retinoblastoma and uveal melanoma. F1000Res 2018;7:476 CrossRef

2. Kivelä T. The Epidemiological Challenge of the Most Frequent Eye Cancer: Retinoblastoma, An Issue of Birth and Death. BMJ Publishing Group Ltd; 2009

3. Abramson DH, Shields CL, Munier FL, et al. Treatment of retinoblastoma in 2015: agreement and disagreement. JAMA Ophthalmol 2015;133:1341-47 CrossRef Medline

4. Shields CL, Bianciotto CG, Jabbour P, et al. Intra-arterial chemotherapy for retinoblastoma: report No. 1, control of retinal tumors, subretinal seeds, and vitreous seeds. Arch Ophthalmol 2011;129:1399-1406 CrossRef Medline

5. Shields CL, Jorge R, Say EAT, et al. Unilateral retinoblastoma managed with intravenous chemotherapy versus intra-arterial chemotherapy. Outcomes based on the International Classification of Retinoblastoma. Asia Pac J Ophthalmol (Phila) 2016;5:97-103

6. Shields CL, Kaliki S, Shah SU, et al. Minimal exposure (one or two cycles) of intra-arterial chemotherapy in the management of retinoblastoma. Ophthalmology 2012;119:188-92 CrossRef Medline

7. Shields CL, Manjandavida FP, Lally SE, et al. Intra-arterial chemotherapy for retinoblastoma in 70 eyes: outcomes based on the International Classification of Retinoblastoma. Ophthalmology 2014;121:1453-60 CrossRef

8. Shields CL, Mashayekhi A, Au AK, et al. The International Classification of Retinoblastoma predicts chemoreduction success. Ophthalmology 2006;113:2276-80 CrossRef

9. Gobin P, Marr B, Dunkel I, et al. Intra-arterial chemotherapy (chemosurgery) in the ophthalmic artery for the treatment of retinoblastoma in children: 3 year experience. J Neurointerv Surg 2009;1:77-78 CrossRef

10. Abramson DH, Daniels AB, Marr BP, et al. Intra-arterial chemotherapy (ophthalmic artery chemosurgery) for group $D$ retinoblastoma. PLoS One 2016;11:e0146582 CrossRef Medline
11. Yamane T, Kaneko A, Mohri M. The technique of ophthalmic arterial infusion therapy for patients with intraocular retinoblastoma. Int J Clin Oncol 2004;9:69-73 CrossRef Medline

12. Abramson DH, Dunkel IJ, Brodie SE, et al. A phase I/II study of direct intraarterial (ophthalmic artery) chemotherapy with melphalan for intraocular retinoblastoma: initial results. Ophthalmology 2008;115:13981404,e1391 CrossRef Medline

13. Abramson DH, Marr BP, Francis JH, et al. Simultaneous bilateral ophthalmic artery chemosurgery for bilateral retinoblastoma (tandem therapy). PLoS One 2016;11:e0156806 CrossRef Medline

14. Shields CL, Bianciotto CG, Jabbour P, et al. Intra-arterial chemotherapy for retinoblastoma: report No. 2, treatment complications. Arch Ophthalmol 2011;129:1407-15 CrossRef Medline

15. Shields CL, Alset AE, Say EAT, et al. Retinoblastoma control with primary intra-arterial chemotherapy: outcomes before and during the intravitreal chemotherapy era. J Pediatr Ophthalmol Strabismus 2016;53:275-84 CrossRef Medline

16. Dalvin LA, Kumari M, Essuman VA, et al. Primary intra-arterial chemotherapy for retinoblastoma in the intravitreal chemotherapy era: five years of experience. Oncol Pathol 2019;5:139-46 CrossRef

17. Kim RS, Dannenbaum MJ, Lin MW, et al. Use of femoral artery ultrasound during intraarterial chemotherapy for children under $10 \mathrm{~kg}$ with retinoblastoma. Retina 2018;38:1420-26

18. Magan T, Khoo CT, Jabbour PM, et al. Intraarterial chemotherapy for retinoblastoma in a 2-month-old infant. Retin Cases Brief Rep 2017;11:24-26

19. Abramson DH, Fabius AW, Issa R, et al. Advanced unilateral retinoblastoma: the impact of ophthalmic artery chemosurgery on enucleation rate and patient survival at MSKCC. PloS One 2015;10: e0145436 CrossRef Medline

20. Abramson DH, Shields CL, Jabbour P, et al. Metastatic deaths in retinoblastoma patients treated with intraarterial chemotherapy (ophthalmic artery chemosurgery) worldwide. Int J Retin Vitr 2017;3:40 CrossRef

21. Munier FL, Mosimann P, Puccinelli F, et al. First-line intra-arterial versus intravenous chemotherapy in unilateral sporadic group $D$ retinoblastoma: evidence of better visual outcomes, ocular survival and shorter time to success with intra-arterial delivery from retrospective review of 20 years of treatment. Br J Ophthalmol 2017;101:1086-93 CrossRef

22. Gobin YP, Dunkel IJ, Marr BP, et al. Intra-arterial chemotherapy for the management of retinoblastoma: four-year experience. Arch Ophthalmol 2011;129:732-37 CrossRef Medline

23. Chen M, Zhao J, Xia J, et al. Intra-arterial chemotherapy as primary therapy for retinoblastoma in infants less than 3 months of age: a series of 10 case-studies. PLoS One 2016;11:e0160873 CrossRef Medline

24. Daniels AB, Froehler MT, Pierce JM, et al. Pharmacokinetics, tissue localization, toxicity, and treatment efficacy in the first small animal (rabbit) model of intra-arterial chemotherapy for retinoblastoma. Invest Ophthalmol Vis Sci 2018;59:446-54 CrossRef Medline

25. Franken E Jr, Girod D, Sequeira F, et al. Femoral artery spasm in children: catheter size is the principal cause. AJR Am J Roentgenol 1982;138:295-98 CrossRef Medline

26. Burrows PE, Benson LN, Williams WG, et al. Iliofemoral arterial complications of balloon angioplasty for systemic obstructions in infants and children. Circulation 1990;82:1697-1704 CrossRef Medline

27. Burrows PE, Benson LN, Babyn P, et al. Magnetic resonance imaging of the iliofemoral arteries after balloon dilation angioplasty of aortic arch obstructions in children. Circulation 1994;90:915-20 CrossRef

28. Perry M. Iatrogenic injuries of arteries in infants. Surg Gynecol Obstet 1983;157:415-18 Medline

29. Fullilove S, Fixsen J. Major limb deformities as complications of vascular access in neonates. Paediatr Anaesth 1997;7:247-50 CrossRef Medline

30. Macnicol M, Anagnostopoulos J. Arrest of the growth plate after arterial cannulation in infancy. J Bone Joint Surg Br 2000;82:172-75 CrossRef Medline 